\title{
Dairy Product
}

National Cancer Institute

\section{Source}

National Cancer Institute. Dairy Product. NCI Thesaurus. Code C413.

Food made from the milk of some mammals, most commonly cows, goats and sheep. 